\title{
Was wirklich zählt
}

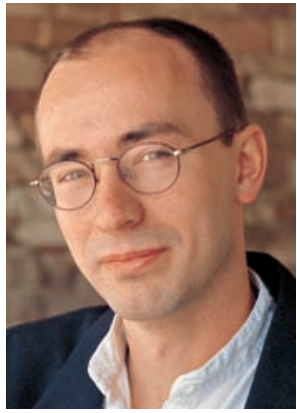

Dr. med. Dieter Schmid, Redaktionsleitung
Schon gehört? Die Krise findet nicht statt. Zumindest nicht für junge Ärzte und solche, die es werden wollen. Während im Gefolge der Finanzmarktkatastrophe die Wirtschaft in den Keller rauscht, merken Mediziner davon zunächst herzlich wenig. Ein Beleg dafür, wie selbstbewusst deutsche Ärzte trotz Rezession ihre Interessen vertreten, ist die aktuelle Tarifforderung des Marburger Bundes. In den Verhandlungen über die Gehälter der Uniklinikärzte verlangt die Ärztegewerkschaft 9 Prozent mehr Lohn. Der MB begründet dies damit, dass die deutschen Ärzte gehaltsmäßig im internationalen Vergleich schlecht abschneiden. In den Niederlanden würden 35, in Großbritannien 40 und in Skandinavien sogar 60 Prozent mehr verdient. Das sei ein Grund, warum mittlerweile 19.000 deutsche Ärzte im Ausland arbeiten. Damit hat der MB natürlich ein gutes Druckmittel. Und keine Frage: Ärzte leisten viel für diese Gesellschaft - deshalb haben sie diese Lohnzuwächse auch verdient. Zur ganzen Wahrheit gehört aber auch, dass die deutschen Medizinergehälter international nur dann Mittelmaß sind, wenn man sich die Industrieländer anschaut. In vielen ärmeren Ländern verdienen Ärzte so wenig, dass ihr Verdienst nicht einmal zum Leben reicht. In unserem Artikel „Wer hat die besten Karten?“ auf S. 26 schlüsseln wir diese Unterschiede auf - damit Sie wissen, wie gut „Ihre Aktien“ global betrachtet stehen.

Alle, die später nicht nur auf Karriere und Verdienst bauen möchten, finden in unserem Artikel „Frachter der Hoffnung“ auf S. 8 einen wertvollen Tipp. Wir berichten von der Hilfsorganisation „Mercy Ships“, die medizinisches und technisches Know-how zu Menschen transportiert, die sich sonst nie eine ärztliche Behandlung leisten könnten. Alle Beteiligten opfern für dieses Engagement nicht nur Urlaub und Freizeit. Sie zahlen sogar dafür, mitmachen zu dürfen! Warum tun die das? Ein junger Arzt, der vor kurzem zum ersten Mal auf der „MS Africa Mercy“ mitgearbeitet hat, fasst die Antwort in einem Satz zusammen: „Durch einen solchen Einsatz merkt man, was tatsächlich im Leben zählt!“

Zum Schluss noch ein Tipp in eigener Sache: Ab diesem Heft ist Via medici für Abonnenten im Fachzeitschriftenportal „Thieme eJournals“ verfügbar. Via medici ist hier in guter Gesellschaft. Aktuell stehen dort bereits die Inhalte von 130 hochwertigen Journals online. Künftig werden Sie also alle Via medici-Artikel von jedem Computer mit Internetanschluss aufrufen können. Mehr über dieses Angebot auf S. 57. Wir hoffen, dass Ihnen Via medici so noch ein kleines Stückchen näherrückt ;-)

Ich wünsche Ihnen ein glückliches neues Jahr 2009!

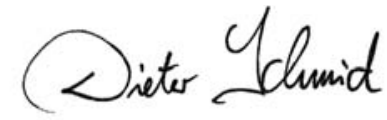

ONLINE-UMFRAGE

Gold, Geld, gute Tat? Was glänzt am hellsten?

Unser Artikel „Wer hat die besten Karten?“ (S. 26) zeigt, in welchen Fachbereichen und Ländern ein Arzt am ehesten so viel Geld verdient, dass er sich mit hoher Wahrscheinlichkeit irgendwann als wohlhabend bezeichnen kann. Doch welche Rolle spielt für Sie der „pekuniäre Aspekt“ überhaupt? Haben Sie sich auch deswegen für das Fach Medizin entschieden, weil Sie in Zukunft als Chefarzt oder niedergelassener Orthopäde bzw.
Radiologe ein gutbetuchtes Leben führen möchten? Oder steht für Sie absolut im Vordergrund, dass Sie dieses Fach lieben, das Studium spannend finden und später mit Ihrer Profession Menschen helfen möchten?

- Gehört der gute Verdienst zu Ihren primären Gründen, aus denen Sie Medizin studieren?

Stimmen Sie ab und sagen Sie Ihre Meinung unter: www.thieme.de/viamedici/aktuelles/aktion/ miniumfrage1_09.html
- Ergebnis der Umfrage in Via medici 5.08: Wir fragten, ob Sie sich durch Ihr Studium gut auf Notfälle vorbereitet fühlen. Erschreckend: 68 Prozent der Teilnehmer verneinten diese Frage. Grund genug für uns, eine neue Serie mit Kurzartikeln zum Thema Alltags-Notfälle zu starten. Den ersten finden Sie auf $\mathbf{S}$. 38. Thema: Was tun, wenn man eine Person auffindet, bei der man nicht weiß, ob sie bewusstlos ist oder „nur“ einen Rausch ausschläft. Kommentare der Umfrageteilnehmer finden Sie unter: ...। aktuelles/aktion/miniumfrage5_08.html 